\title{
Fabrication and characterization of porous silicon layer prepared by photo-electrochemical etching in $\mathrm{CH}_{3} \mathrm{OH}$ :HF solution
}

\author{
Hasan A. Hadi ${ }^{1}$, Raid A. Ismail ${ }^{2}$, Nadir F. Habubi ${ }^{1, *}$ \\ ${ }^{1}$ Physics Department, Education Faculty, The University of Mustansiriya, Baghdad, Iraq \\ ${ }^{2}$ Department of Applied Sciences, The University of Technology, Baghdad, Iraq \\ *E-mail address: nadirfadhil@yahoo.com
}

\begin{abstract}
Porous silicon (PS) has been fabricated by Photo-electrochemical etching. Porous silicon was anodized on n-type Si in light using a current density of $20 \mathrm{~mA} / \mathrm{cm}^{2}$ for $10 \mathrm{~min}$. The porous structure formation was confirmed using XRD and AFM studies. The root mean square (RMS) roughness of the Porous silicon layer is found to be around $47.5 \mathrm{~nm}$ and the ten point height was $317 \mathrm{~nm}$. The average of pores diameter was $419.98 \mathrm{~nm}$, and the grain growth is columnar with a (211) preferred orientation. The grain size of the PS was estimated from the Scherer's formula and found to be $73 \mathrm{~nm}$. All the properties of the porous silicon layer, such as porosity and the thickness depend on the anodization parameters. The porosity $(\mathrm{P})$ was approximately $77 \%$. The thickness of the layer formed during an anodization in constant current was $3.54 \mathrm{~nm}$ in gravimetric method, while its value was $1.77 \mathrm{~nm}$ by using the theoretical relation.
\end{abstract}

Keywords: porous silicon; photo-electrochemical etching (PECE); porosity; thickness; XRD; AFM

\section{INTRODUCTION}

Porous silicon is one of the most promising materials, because it can emit visible range of light at room temperature. One of the most important characteristics of the PS layers its very large and reactive internal surface so that, one should expect, that this internal surface would play an important role in those specific properties of PS layers which make this material so different from bulk one [1]. The easy and cheap fabrication, associated with the good optical properties of such samples, increases the field of potential applications of PS in integrated optics and photonics even more [2]. X-ray diffraction XRD measurements present a noticeable feature related to the crystalline. Each diffraction peak consists of a sharp peak and broad diffraction around the peak [3]. In this paper, we report the fabrication of porous silicon layers on c-Si using anodic with laser assistant procedure. In order to analysis the quality of the porous layer by gravimetric method; we have used XRD and AFM image techniques. 


\section{EXPERIMENTAL DETAILS}

Porous silicon layer were produced using monocrystalline silicon wafers n-type, with resistivity of $10 \Omega . \mathrm{cm}$. The silicon wafers used in this work were n-type phosphorus silicon wafer with (111) - orientation. The Si (111) samples were etched into a mixture of $40 \% \mathrm{HF}$ : purity Methanol (99.9\%) (1:1) for 10 minutes with a current densities of $20 \mathrm{~mA} / \mathrm{cm}^{2}$, and subjected to an external illumination with a $30 \mathrm{~mW}$ diode laser $650 \mathrm{~nm}$ The simplest cell which can be used to anodize silicon is shown in Figure 1. Methanol and alcohol are used commonly to clean the wafer by using ultrasonic bath for few minutes.

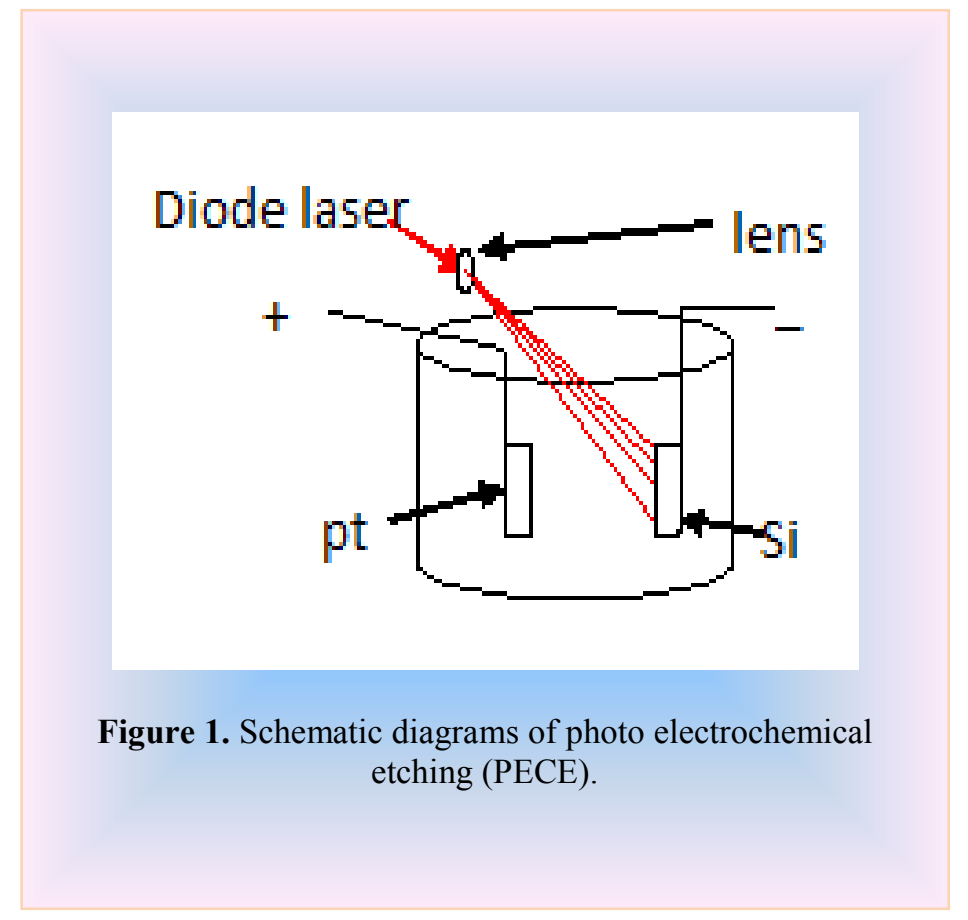

Finally, they were rinsed in distilled water treated ultrasonically followed by drying in a hot air stream. Back side of the samples was coated with thick Aluminum layer. The evaporation is performed in a vacuum pressure of $10^{-6}$ torr, using an evaporation plant model "E306 A manufactured by Edwards high vacuum". In this work an AA 3000 Scanning Probe Microscope AFM system to estimate the surface measurement using. The XRD (shimadzu -6000) system was used for x-ray diffraction measurements. They were then placed into the x-ray $(\mathrm{Cu} \mathrm{K \alpha} 1$ line $\lambda=1.5406 \mathrm{~A})$. The sample was scanned from 25 to 40 degrees 2Theta. The virgin wafer is first weighed before anodisation $\left(\mathrm{m}_{1}\right)$, then just after anodisation $\left(\mathrm{m}_{2}\right)$ and finally after dissolution of the whole porous layer in a molar $\mathrm{NaOH}$ aqueous solution $\left(\mathrm{m}_{3}\right)$. Uniform and rapid stripping in the $\mathrm{NaOH}$ solution was obtained when the PS layer is covered with a small amount of ethanol which improves the infiltration of the aqueous $\mathrm{NaOH}$ in the pores. The porosity is given simply by the equation [4 


$$
P_{\%}=\left(m_{1}-m_{2}\right) /\left(m_{1}-m_{3}\right)
$$

From these measured masses, it is also possible to determine the thickness of the layer according to the equation [4]:

$$
d=\left(m_{1}-m_{3}\right) /(D \times A)
$$

Where $\mathrm{D}$ is the density of bulk silicon, and $\mathrm{A}$ is the wafer area exposed to HF during anodization. In gravimetric method, "Mettler AE-160 digital with accuracy of $0.0001 \mathrm{gm}$ " is used to weight the samples. XRD was used to investigate the size of the crystallites of the porous silicon. The average grain size (crystallite size) corresponds to the average diameter (L) of the crystallite columns which can be calculated by using Debye-Scherrer formulas shown in equation (4) [5].

$$
L=0.9 / F W H M \cdot \cos (\theta)
$$

Where the FWHM is the full width at the half maximum of the characteristic spectrum in units of radians, $\mathrm{L}$ and $\lambda$ are in $\mathrm{nm}$. For diamond structure of silicon, the lattice constant is considered to be a function of interplanar spacing $d_{h k l}$ by using equation (5) [5]:

$$
a=d_{h k l}\left(h^{2}+k^{2}+l^{2}\right)^{1 / 2}
$$

Where $h k l$ are Miller indices.

\section{RESULTS AND DISCUSSION}

The porosity of porous silicon layer has been calculated by measuring the weight of the samples before and after etching process as well as the weight of sample after removing of porous silicon layer. The porosity (P) of approximately $77 \%$ was calculated using Eq. (1). The thickness of porous layer (d) of $3.54 \mathrm{~nm}$ was calculated using Eq.(2). While the thickness (d) was $1.77 \mathrm{~nm}$ by using theoretical relation [6]:

$$
d=R \times J^{x} T
$$

Where $d$ is the layer thickness,

$R=0.0000105, x=0.96$ and $\mathrm{T}$ etching time.

The chemical etching seems to be nonuniform at the early stages. The order of magnitude of the so called critical depth is of about 1 to $2 \mu \mathrm{m}$ for n-type porous silicon [2].

X-ray diffraction analyses were carried out in the $29^{\circ}-34^{\circ}$ range of $2 \theta$. The figures $2-$ 3 , show the XRD spectra of c-Si and porous silicon layers. This pattern confirm the formation of porous layer with a small broader peak centered near $33.1^{\circ}$ and $33.2^{\circ}$. Figure 3 , confirm the formation of pores on the crystalline silicon surface, a small broadening and splitting peak of the porous silicon layer, and also it compares with the XRD spectra of the c- Si. The intensity of the porous silicon peak decreases. A strong peak of (c-Si) fresh silicon shows a very sharp 
peak at $2 \theta=28.38^{\circ}$ oriented only along the (111) direction is observed confirming the monocrystalline structure of the Si layer which belongs to the (111) reflecting plane of Si of cubic structure (according to ICDD N 1997and 2011 JCPDS) while Porous silicon layer which belongs to the (211) orientation. The increase in lattice constant has also been observed in porous silicon by Young et al., and suggested that the increase in lattice constant arises from stress induced by growth of a native oxide on the surface on the pore structures [7].

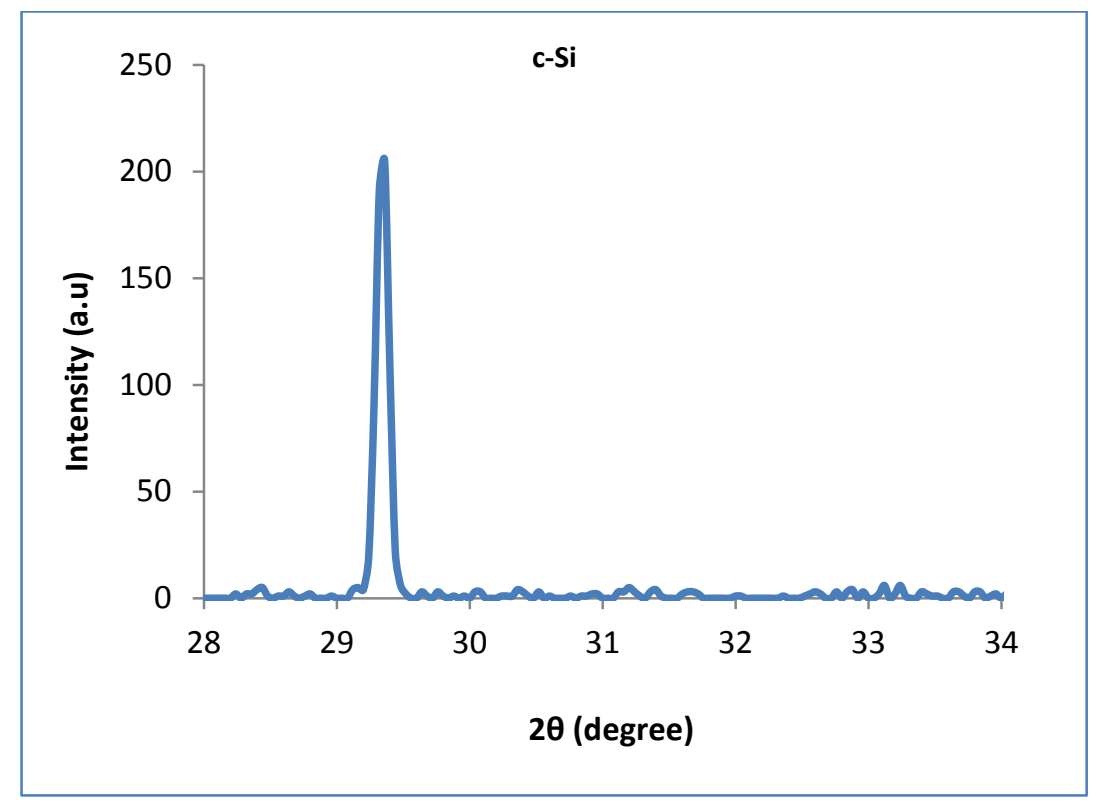

Figure 2. XRD spectra of c-Si sample before etching.

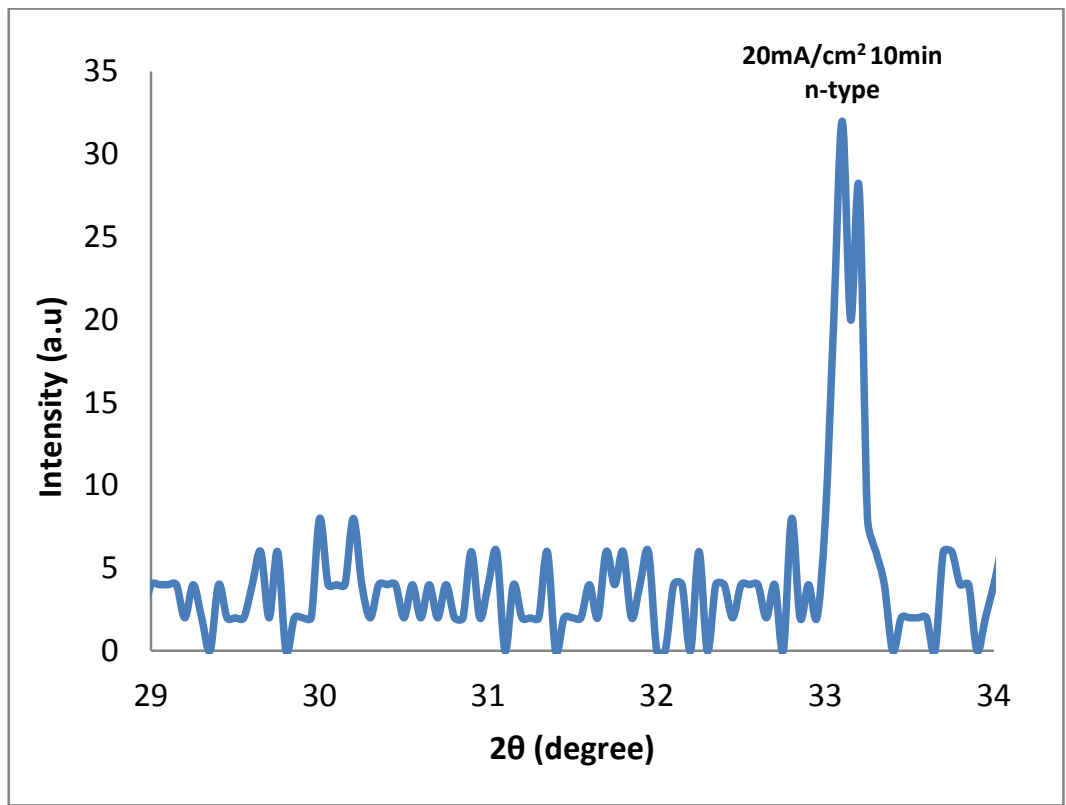

Figure 3. XRD spectra of PS samples anodized for 10 min etching time at $20 \mathrm{~mA} \cdot \mathrm{cm}^{-2}$ etching current density. 
The average diameter of crystallites resulting of the broadening in a spectrum at 20 $\mathrm{mA} / \mathrm{cm}^{2}$ etching current density was $73 \mathrm{~nm}$. A broad reflection indicates that its average crystal size is smaller than that of crystalline silicon according to the Scherrer equation, where the full width half maximum FWHM of c-Si was $(0.1168)$ while it was $(0.1665)$ for porous silicon layer.

Atomic force microscopy: As a result, AFM does only allow imaging of the top end of the pores, which is a general disadvantage of this technique compared with electron microscopy [5]. The advantage of this measurement mode is that the AFM analysis can be done with very small forces [8]. The AFM picture taken on PS grown on $n$ type Si shows the usual rough surface structure. Figures 4-5, show two and three-dimensional AFM image of the as-anodized porous silicon surface structure formed on n-type for $10 \mathrm{~min}$ time etching at $20 \mathrm{~mA} / \mathrm{cm}^{2}$. This image shows that the film is homogeneous and has a large number of vertically aligned (columnar) grains. The scan area film for AFM analysis was $5 \mu \mathrm{m} \times 5 \mu \mathrm{m}$. The surface was very smooth, the root mean square (RMS) of roughness was measured and found to be around $47.5 \mathrm{~nm}$ and the ten point height was $317 \mathrm{~nm}$. Table 1 reported that the average of pores diameter was $419.98 \mathrm{~nm}$ according to the statistical image of pores analyses.

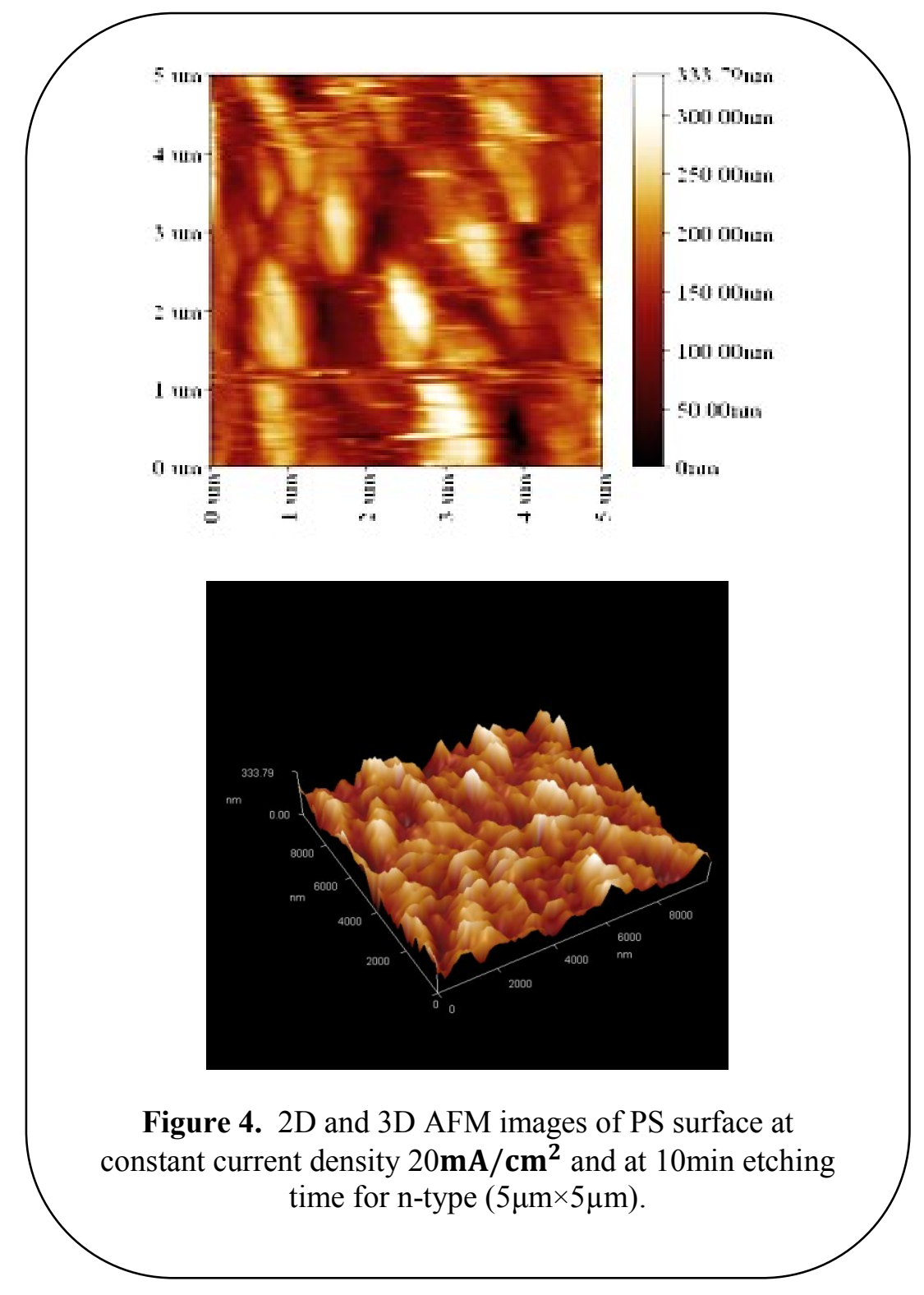




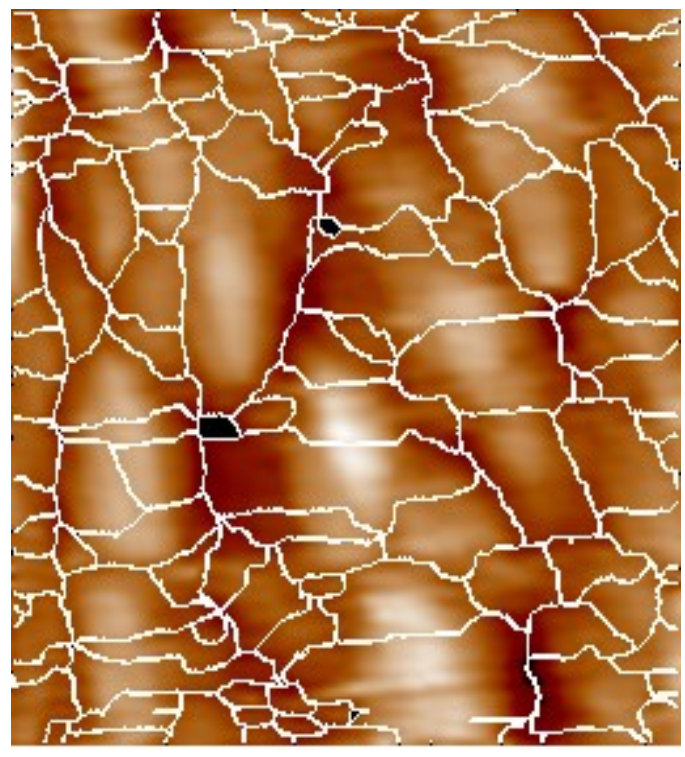

Pixels $=[256,256] \quad$ Size $=[5000.00 \mathrm{~nm}$

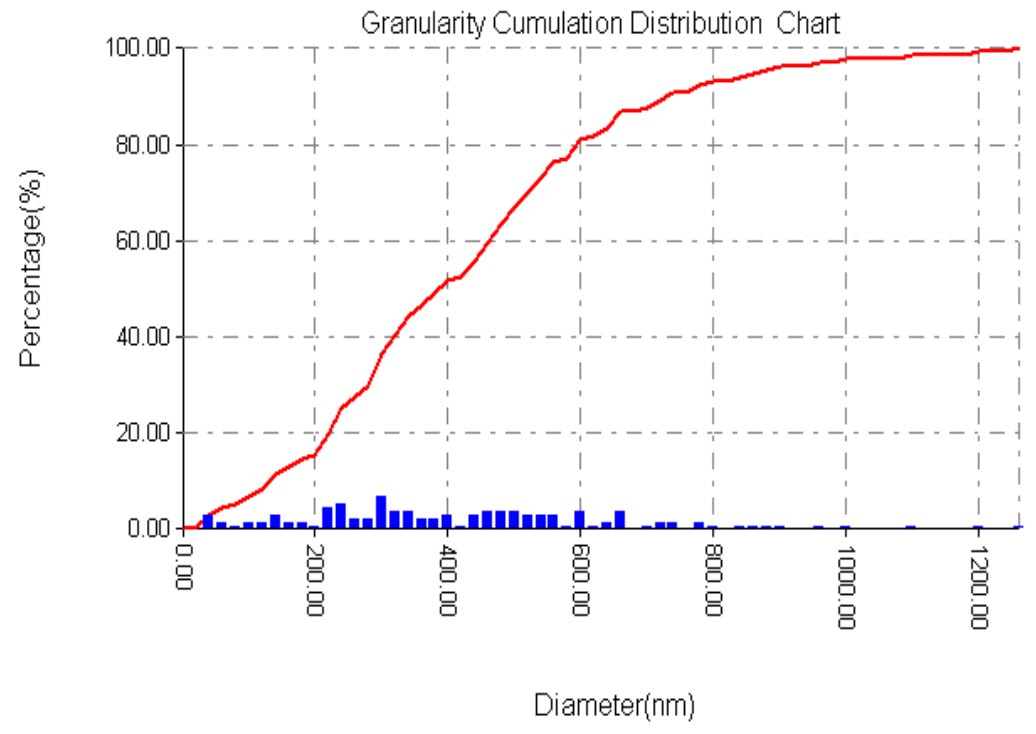

Figure 5. Granularity Cumulation Distribution Chart of diameter of porous silicon at $20 \mathrm{~mA} / \mathrm{cm}^{2}$ etching current density 
Table 1. Granularity Cumulation Distribution Report Avg. diameter $419.98 \mathrm{~nm}$ where $<=10 \%$ Diameter: $120.00 \mathrm{~nm},<=50 \%$ Diameter: $380.00 \mathrm{~nm}$, and $<=90 \%$ Diameter: $720.00 \mathrm{~nm}$.

\begin{tabular}{|c|c|c|c|c|c|c|c|c|}
\hline $\begin{array}{c}\text { Diameter } \\
(\mathrm{nm})<\end{array}$ & $\begin{array}{c}\text { Volume } \\
(\%)\end{array}$ & $\begin{array}{c}\text { Cumulation } \\
(\%)\end{array}$ & $\begin{array}{c}\text { Diameter } \\
(\mathrm{nm})<\end{array}$ & $\begin{array}{c}\text { Volume } \\
(\%)\end{array}$ & $\begin{array}{c}\text { Cumulation } \\
(\%)\end{array}$ & $\begin{array}{c}\text { Diameter } \\
(\mathrm{nm})<\end{array}$ & $\begin{array}{c}\text { Volume } \\
(\%)\end{array}$ & $\begin{array}{c}\text { Cumulation } \\
(\%)\end{array}$ \\
\hline 40.00 & 3.05 & 3.05 & 360.00 & 2.29 & 46.56 & 700.00 & 0.76 & 87.79 \\
60.00 & 1.53 & 4.58 & 380.00 & 2.29 & 48.85 & 720.00 & 1.53 & 89.31 \\
80.00 & 0.76 & 5.34 & 400.00 & 3.05 & 51.91 & 740.00 & 1.53 & 90.84 \\
100.00 & 1.53 & 6.87 & 420.00 & 0.76 & 52.67 & 780.00 & 1.53 & 92.37 \\
120.00 & 1.53 & 8.40 & 440.00 & 3.05 & 55.73 & 800.00 & 0.76 & 93.13 \\
140.00 & 3.05 & 11.45 & 460.00 & 3.82 & 59.54 & 840.00 & 0.76 & 93.89 \\
160.00 & 1.53 & 12.98 & 480.00 & 3.82 & 63.36 & 860.00 & 0.76 & 94.66 \\
180.00 & 1.53 & 14.50 & 500.00 & 3.82 & 67.18 & 880.00 & 0.76 & 95.42 \\
200.00 & 0.76 & 15.27 & 520.00 & 3.05 & 70.23 & 900.00 & 0.76 & 96.18 \\
220.00 & 4.58 & 19.85 & 540.00 & 3.05 & 73.28 & 960.00 & 0.76 & 96.95 \\
240.00 & 5.34 & 25.19 & 560.00 & 3.05 & 76.34 & 1000.00 & 0.76 & 97.71 \\
260.00 & 2.29 & 27.48 & 580.00 & 0.76 & 77.10 & 1100.00 & 0.76 & 98.47 \\
280.00 & 2.29 & 29.77 & 600.00 & 3.82 & 80.92 & 1200.00 & 0.76 & 99.24 \\
300.00 & 6.87 & 36.64 & 620.00 & 0.76 & 81.68 & 1260.00 & 0.76 & 100.00 \\
320.00 & 3.82 & 40.46 & 640.00 & 1.53 & 83.21 & & & \\
340.00 & 3.82 & 44.27 & 660.00 & 3.82 & 87.02 & & & \\
\hline
\end{tabular}

\section{CONCLUSION}

Porous structures were prepared on $\mathrm{n}-\mathrm{Si}$ single crystal wafers by a photoelectrochemical at low current density and etching time. The surface of the PS layers was investigated by the XRD and AFM .This study shows that PS layer thickness has a different value, depending on the method of calculation either experimentally or theoretical .

\section{ACKNOWLEDGEMENTS}

The assistance from the University of Technology-Department of Applied Sciences -Laser Branch and national center for construction laboratories are acknowledged for providing the facilities devices of this work.

\section{Reference}

[1] M. Draghici, M. Ciurea, V. Iancu, XLV - XLVI, S. FizicaStării Condensate, Tomul, (1999, 2000) 86-90.

[2] D. Buttard, D. Bellet, G. Dolino, Journal of Applied Physics 83 (1998) 5814-5822.

[3] Yukio H. Ogata, Naoki Yoshimi, Ryo Yasuda, Takashi Tsuboi, Tetsuo Sakka, Akira Otsuki Journal of Applied Physics 90 (2001) 6487-6492. 
[4] O. Bisi, S. Ossicini, L. Pavesi, Surface Science Reports 38 (2000) 1-126.

[5] Khalid Omar, Y. Al-Dour, Asmiet Ramizy, Z. Hassan, Superlattices and Microstructures 50 (2011) 119-127.

[6] D. Buttard, D. Bellet, G. Dolino, J. Appl. Phys. 79 (1996) 8060-8070.

[7] I. M. Young, M. I. Beale, J. D. Benjamin, Applied Physics. Lett. 46 (1985) 1133-1135.

[8] D. C. Chang, V. Baranauskas, I. Doi, Journal of Porous Materials 7 (2000) 349-352. 